\title{
Burden of Moderate and Severe Head Injury in Kashmir Valley
}

\author{
Irfan Bhat ${ }^{1} \quad$ Nayil Malik ${ }^{1} \quad$ Kaiser Kareem ${ }^{1} \quad$ Altaf Ramzan ${ }^{1} \quad$ Hilal Sheikh ${ }^{2} \quad$ Abrar Wani \\ Sarbjit Singh ${ }^{1}$ Sajad Arif ${ }^{1}$ Abdul Rashid ${ }^{1}$
}

${ }^{1}$ Department of Neurosurgery, Sher-i-Kashmir Institute of Medical

Address for correspondence Nayil Malik, MS, MCh, Department of Sciences, Srinagar, Jammu and Kashmir, India

${ }^{2}$ Department of Neurology, Shri Maharaja Hari Singh Hospital,

Srinagar, Jammu and Kashmir, India Neurosurgery, Sher-i-Kashmir Institute of Medical Sciences, Srinagar, Jammu and Kashmir 190011, India (e-mail: nayilkhursh@gmail.com).

Indian J Neurotrauma:2021;18:79-83

\begin{abstract}
Background Head injury is a major health hazard throughout the world. Overall, the mortality/morbidity has not changed much in the last few decades. In developing nations, the situation is worse.

Methods The study was conducted for a period of 1 year. The data collected include demographic profile, mode, circumstances and timing of the injury, neurological assessment using Glasgow Coma Scale (GCS) scoring, computed tomography (CT) scan findings, type of management, and outcome.

Results Transport-related injuries and falls were the common cause of head injury, with more severe injuries seen in patients without wearing helmets and seat belts. The

Keywords

- head injury

- contusion

- subdural hematoma

- moderate head injury

- severe head injury

- burden of head injury youth is at high risk of receiving head injuries. The summer season showed a maximum incidence of head injuries. The most common lesions on CT scan were linear fracture of the skull and brain contusion. Mortality rate was $26 \%$ and it correlated with the GCS at presentation.

Conclusion Head injury mostly affects young people and males outnumber females. Road traffic accident is the major cause. People not abiding by the traffic rules, such as wearing helmets and seat belts, were at high risk of developing head injury and poor outcome.
\end{abstract}

\section{Introduction}

Head injury is a major cause of morbidity and mortality worldwide, especially among the youth. ${ }^{1}$ Despite marked improvements in the management of traumatic brain injury (TBI), the mortality/morbidity has not changed much in the last few decades, owing to the escalation of vehicular traffic. Two-wheelers are more dangerous to travel than four-wheelers. ${ }^{2}$ In India, more than 1 million accidents occur every year resulting in 150,000 deaths, with 1 accident per minute and 1 death every 4 to 5 minutes. Nearly 350 deaths occur due to motor vehicle accidents every day in India. ${ }^{3}$ While in Europe there is a decreasing incidence of head injury in adults because of the introduction of safety

published online

September 29, 2020
Dol https://doi.org/

$10.1055 / \mathrm{s}-0040-1717217$ ISSN 0973-0508. belts and crash helmets, in the underdeveloped world it is a serious public health problem. ${ }^{3}$

\section{Materials and Methods}

This was a 1-year prospective study conducted in the Department of Neurosurgery, Sher-i-Kashmir Institute of Medical Sciences, Srinagar, Jammu and Kashmir, India, between November 2015 and October 2016. This single institute caters to the entire 7-million population for head injury patients in the Kashmir and Ladakh division.

The severity of the head injury was assessed using the Glasgow Coma Scale (GCS) $)^{4}$ taken on admission and patients

(C2020. Neurotrauma Society of India.

This is an open access article published by Thieme under the terms of the Creative Commons Attribution-NonDerivative-NonCommercial-License, permitting copying and reproduction so long as the original work is given appropriate credit. Contents may not be used for commercial purposes, or adapted, remixed, transformed or built upon. (https://creativecommons.org/licenses/by-nc-nd/4.0/).

Thieme Medical and Scientific Publishers Pvt. Ltd. A-12, 2nd Floor, Sector 2, Noida-201301 UP, India 
were classified as GCS of 13 to 15,9 to 12 , and 3 to 8 for mild, moderate, and severe head injuries, respectively. All moderate and severe (GCS 3-12) head-injured patients were enrolled in the study.

All the patients were first resuscitated in the accident and emergency department according to the Advanced Trauma Life Support. All patients were subjected to computed tomography (CT) scan of the head. Depending on the type of injury and CT scan findings, the patients were treated either conservatively or by surgery. Specific criteria used for surgical intervention were:

Extradural hematoma: > $30 \mathrm{~mL}$ volume, > $15 \mathrm{~mm}$ thick, > $5 \mathrm{~mm}$ midline shift irrespective of GCS.

Acute subdural hematoma: Thickness $>10 \mathrm{~mm}$, midline shift $>5 \mathrm{~mm}$ irrespective of GCS.

For a comatose patient with less than $10-\mathrm{mm}$ thick clot or less than 5-mm shift, surgical intervention was done if GCS dropped by 2 or more or if the patient developed anisocoria/ bradycardia.

Traumatic contusions/intraparenchymal hematomas: Progressive neurological deterioration attributable to the lesion, signs of mass effect on CT or volume of frontal/temporal contusions $>20 \mathrm{~mL}$ with $>5 \mathrm{~mm}$ midline shift and/or cisternal compression, or volume of contusion $>50 \mathrm{~mL}$.

Depressed fractures: Fractures depressed greater than the thickness of the cranium.

Patients were followed up for 3 months after the injury. The length of hospital stay and mortality were recorded. Patients were followed at 3 months after discharge using the Glasgow Outcome Scale (GOS) ${ }^{5}$ for assessment. Data was summarized in the form of proportions and frequency tables for categorical variables. Fisher's exact test was used to calculate the $p$-value, the significance was set at $5 \%$. Statistical Package for Social Sciences (SPSS) software, version19 (IBM, Illinois, United States) was used.

\section{Results}

\section{Demography}

The total number of moderate and severe head injuries admitted was 430 , with $59.30 \%$ (255/430) having moderate and $40.70 \%$ (175/430) having severe head injuries.

\section{Age and Gender}

The average age was 24.8 years and the most common age group involved was 19 to 30 years $(118,27.44 \%)$. The gender ratio was $2.6: 1$ in favor of males $(311,72.32 \%)$.

\section{Mode, Circumstances, Timing, and Severity of the Injury} The major cause of head injury was road traffic accidents (RTAs) (-Fig. 1). Two-wheeler-associated injuries were seen in $47.55 \%$ (107/225) (-Fig. 2). The maximum number of RTAs took place on secondary road systems (63, 41.45\%) (primary road system [national highways], secondary road system [state highways], and major interdistrict roads [tertiary road system], smaller district roads, and rural roads) during 12 to 6 p.m. (97, 43.11\%). College students were mostly involved in RTAs (-Fig. 3). The peak in the

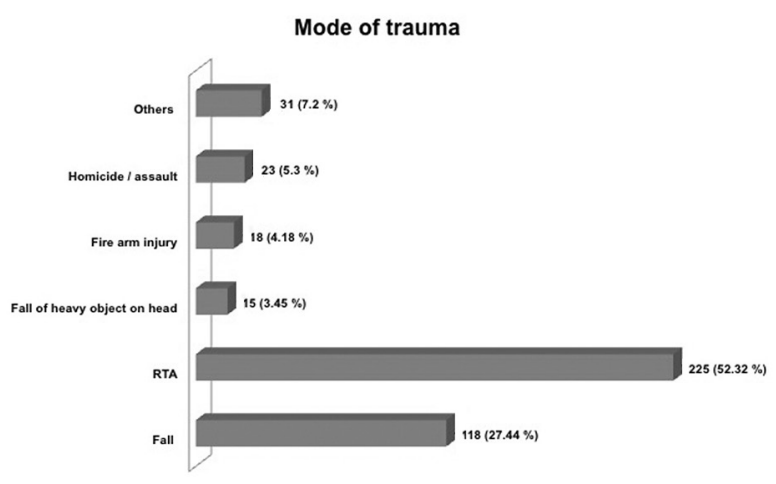

Fig. 1 Mode of trauma.

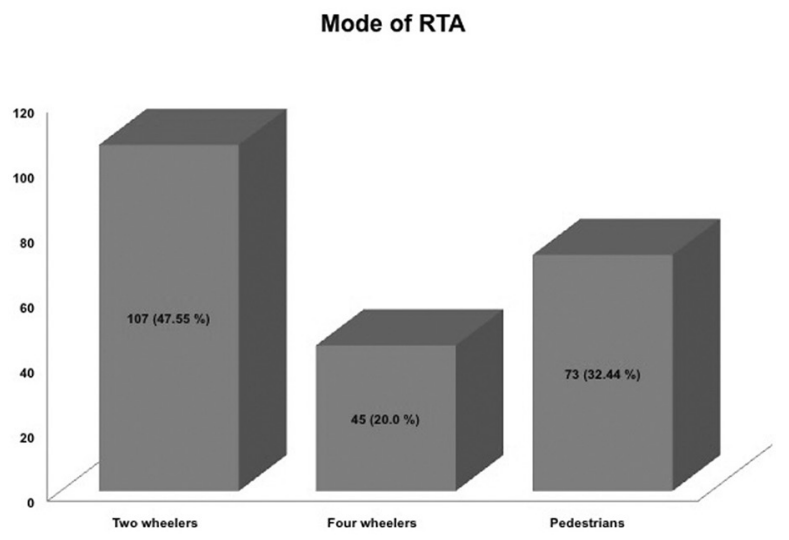

Fig. 2 Different modes of road traffic accident (RTA).

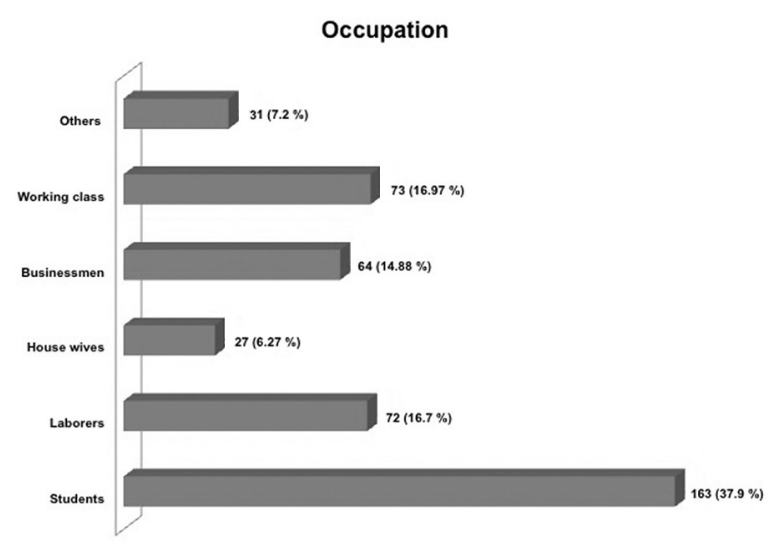

Fig. 3 Profile of occupation.

incidence of RTA was seen in summer (July) (49, 11.39\%) (-Fig. 4).

Most of the RTAs occurred while covering the mid-third of the planned distance of the route (92, 40.89\%) (-Fig. 5), possibly because the drivers tend to be more complacent in the latter part of the journey.

Moderate head injury was seen in 59.30\% (255/430) patients and severe in 40.69\% (175/430) patients. Among two-wheeler accidents, 61.68\% (66/107) pillion riders were 
injured and 38.31\% (41/107) drivers were injured. In contrast to this in four-wheeler accidents, more front passengers were involved than backseat passengers, 33.33\% (15/45) versus $20 \%$ (9/45). Drivers without helmets were prone to get severe head injuries and it was statistically significant $(p=0.0001)$. Similarly, passengers not wearing seat belts $(36,80.0 \%)$ were injured more than those wearing seat belts $(9,20.0 \%)$ (-Table 1$)$.

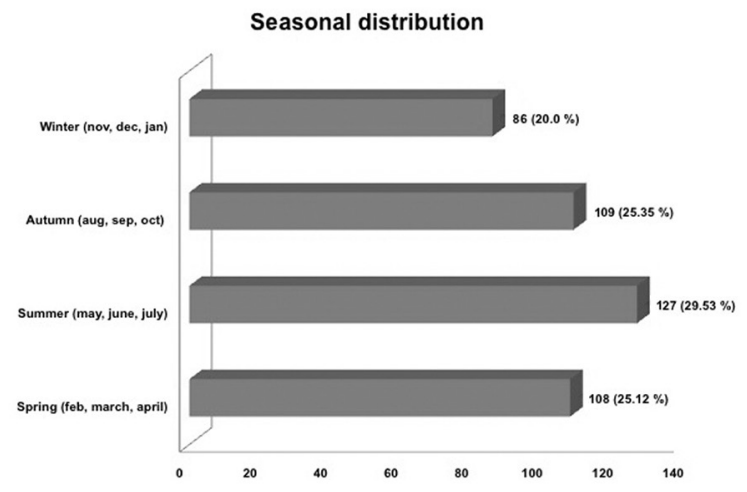

Fig. 4 Seasonal distribution.

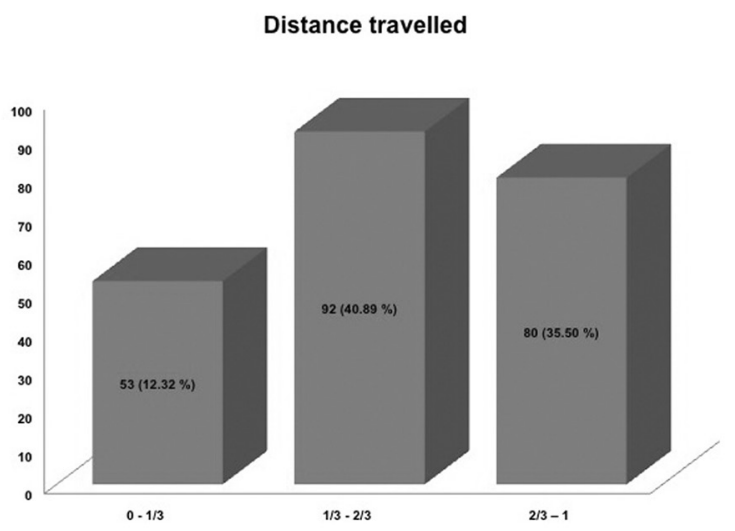

Fig. 5 Distance traveled.

Table 1 Relation of protective gears with severity of head injury and mortality

\begin{tabular}{|l|l|l|l|}
\hline GCS & $3-8$ & $9-12$ & $p$-Value \\
\hline Seat belt $(n=9)$ & 3 & 6 & \\
\hline No seat belt $(n=36)$ & 31 & 5 & $0.0033^{\text {a }}$ \\
\hline Helmet $(n=24)$ & 5 & 19 & \\
\hline No helmet $(n=83)$ & 68 & 15 & $0.0001^{\text {a }}$ \\
\hline Mortality & $88 / 175$ & $24 / 255$ & \\
\hline No mortality & $151 / 175$ & $167 / 255$ & $0.0002^{\text {a }}$ \\
\hline
\end{tabular}

Abbreviation: GCS, Glasgow coma scale.

aStatistically significant.

\section{Type of Head Injury and Management}

The most common injury observed on CT scan was a linear fracture of the skull bone (210/430) followed by contusions (-Fig. 6). Note that $45.58 \%(196 / 430)$ cases were managed conservatively and $54.42 \%(234 / 430)$ cases required surgical intervention.

\section{Length of Hospital Stay and Mortality}

The average duration of hospital stay was 6.71 days (2,888 days for 430 patients). It was 4.93 days (967 days for 196 patients) in patients managed conservatively and 8.21 days (1,921 days for 234 patients) in those with surgical intervention. The hospital stay was 5.29 days (1,350 days for 255 patients) in moderate head injury cases and 8.79 days (1,538 days in 175 patients) in severe head injury cases. The overall mortality was $26 \%(112 / 430)$. It was more in patients with a severe head injury as compared with the group with moderate head injury ( $p=0.0002$; - Table 1 ).

\section{Follow-Up}

GOS was found to be worse for the patients presenting with GCS 3 to 8 (GOS 1-3) than those presenting with a GCS of 9 to 12 (GOS 4-5) (-Fig. 7).

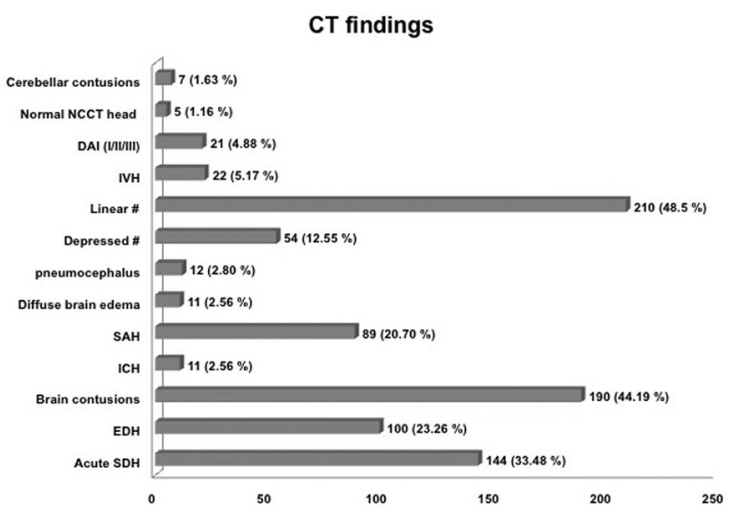

Fig. 6 Radiological profile of patients.

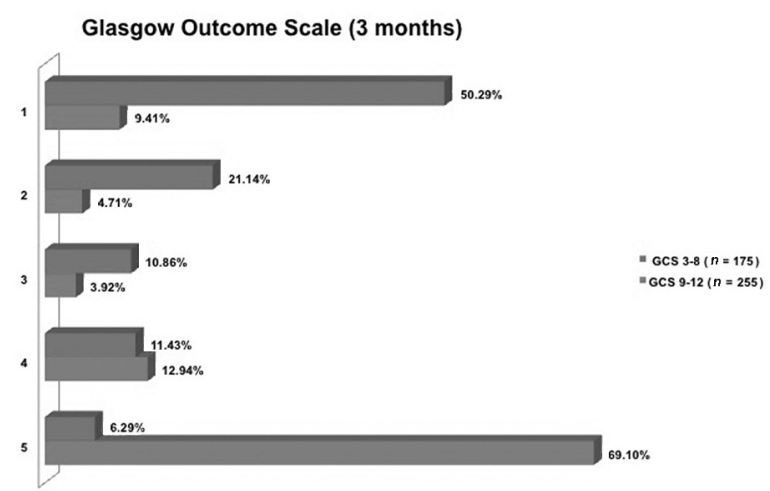

Fig. 7 Glasgow Outcome Scale score at 3 months. 


\section{Discussion}

RTAs are a global problem especially in the developing world. ${ }^{2,6,7}$ In our study, RTA was the major cause of head trauma followed by fall from height. Fall from walnut trees forms a special group of victims in the walnut season (October-November) owing to the slippery nature of the walnut trees and the almost nonexistent use of protective harnesses by the people involved in this sector., ${ }^{8,9}$

Males $(311,72.32 \%$ ) by far outnumbered the females, by a ratio of 2.6:1. The male preponderance in terms of head injuries is because the males being the primary source of economy in most of the families are exposed to work-related hazards, and hence have more exposure to the outside environment than the female. ${ }^{1,10}$

The highest number of patients are in the age group of 19 to 30 years $(118,27.44 \%)$, while the minimum number of patients are in the extremes of age ( $0-2$ years, $2.6 \%$; $71-80$ years, $1.16 \%)^{6,11}$ owing to the fact that the most mobile age group is that of young people who go out for work and daily chores, while at the extremes of ages, the people stay indoors and are less vulnerable to unnatural events like vehicular trauma, assaults, falls, etc. Unlike some studies ${ }^{3}$ wherein it was observed that the incidence of head injury is rising in the elderly because of a high frequency of self-falls, we did not notice such a trend in our study. The reasons put forward for this new trend is various drug treatments in the elderly population resulting in hypotension, dizziness, and vertigo. ${ }^{12}$

The majority of the RTAs in our study occurred between 12 and 6 p.m. (97, 43.11\%) and toward the latter part of the journey. This time range corresponds to the increase in the fatigue level of drivers and reduced attention with a consequent failure to abide by traffic rules, associated with poor infrastructure of the roads like the absence of footpaths, a paucity of zebra crossings, street lights, and traffic personnel. ${ }^{13-15}$ The maximum number of RTAs occur on secondary $(63,41.45 \%)$ and tertiary road systems $(48,31.58 \%)$. Rural roads directly merge with either the interdistrict roads or the national highways and rural traffic generally comprises of untrained drivers not complying to traffic rules and safety precautions, pedestrians who usually tend to neglect personal safety measures while walking on the roads, animals and carts that travel in a haphazard and unpredicted manner, and unsafe and unplanned roads (absence of dividers, speed-breakers, traffic lights, traffic personnel, etc.). The secondary and tertiary road commuters are more likely to have collisions with stationary objects as roadsides do not have safety grills/pavements. .11,12 $^{1}$

Two-wheeler riders $(107,47.55 \%)$ and pedestrians (73, $32.44 \%$ ) were the majority of those hurt in RTAs. Among two-wheeler victims, pillion riders form the majority (61.68\%) as the driver instinctively takes evasive action while the pillion is caught completely off-guard and most of the time pillion rider is not wearing a helmet. The protective helmet is a major safety measure. ${ }^{1,2}$ The victims with protective helmets $(22.43 \%)$ tend to have a less severe brain injury (moderate TBI, 79.17\%) as compared with those not wearing helmets (77.78\%) (severe TBI, 81.93\%). This is statistically significant. Among the four-wheeler victims, the front seat occupants are more likely to sustain dashboard and windshield impact injuries (66.66\%), especially if not using the seat belts (80.0\%). ${ }^{7,16}$ The victims with protective seat belts tend to have a less severe brain injury (moderate TBI, 66.67\%) as compared with those not wearing safety seat belts (severe TBI, 86.11\%).

Firearm injuries form a small $(18,4.18 \%)$ but important class of injuries in our part of the world owing to the fact that Kashmir is a major conflict zone.

During the summer season, TBIs increase $(29.53 \%)$ as during this season people indulge in more outdoor activities as compared with the other seasons. ${ }^{17,10}$ Also because of harsh winter, people tend to stay indoors and the educational institutes being on vacations there is lesser vehicular traffic and hence fewer accidents.

We managed 259 (60.23\%) patients conservatively (antiedema, antiseizure prophylaxis, and elective ventilation [in specific cases]). We operated 171 (39.76\%) patients, of which 127 (74.27\%) underwent emergency surgical procedures whereas $44(25.73 \%)$ cases were operated in a semiemergency setting. Patients whose GCS decreased corresponding to the increase in the mass effect with signs of herniation on CT scan or an increase in the volume of the bleed/contusion associated with clinical deterioration were candidates for surgical intervention.

Overall mortality in our study was $26 \%$, it was $9.41 \%$ (24/255) for GCS 9 to 12 and 50.28\% (88/175) for GCS 3 to 8. The total hospital stay and the intensive care unit stay for the patients with severe head injury were much higher as compared with those presenting with a moderate head injury. ${ }^{6,11}$

GOS at 3 months was found to be worse (GOS-1-3) for the patients presenting with GCS of 3 to 8 than those presenting with a better GCS. This is in concordance with the studies conducted in many developing as well as developed nations. ${ }^{1,2,17-25}$

\section{Conclusion}

Head injury mostly affects young people, and males outnumber females. RTAs are the major cause. People traveling on two-wheelers are especially at risk. Also, people not abiding by the traffic rules such as wearing helmets and seat belts are at high risk of head injury and poor outcome.

\section{Conflict of Interest}

None declared.

\section{References}

1 Farooqui JM, Chavan KD, Bangal RS, et al. Pattern of injury in fatal road traffic accidents in a rural area of western Maharashtra, India. Australas Med J 2013;6(9):476-482

2 Amaranath JE, Ramanan M, Reagh J, et al. Epidemiology of traumatic head injury from a major paediatric trauma centre in New South Wales, Australia. ANZ J Surg 2014;84(6):424-428

3 Borg J, Röe C, Nordenbo A, Andelic N, de Boussard C, af Geijerstam JL. Trends and challenges in the early rehabilitation of patients with traumatic brain injury: a Scandinavian perspective. Am J Phys Med Rehabil 2011;90(1):65-73 
4 Teasdale G, Jennett B. Assessment of coma and impaired consciousness. A practical scale. Lancet 1974;2(7872) :81-84

5 Jennett B, Bond M. Assessment of outcome after severe brain damage. Lancet 1975;1(7905):480-484

6 Anil MB, Rahul P, Amit A, Joharapurkar SR. Demographic profile, clinical presentation, management options in cranio-cerebral trauma: an experience of a rural hospital in Central India. Pak J Med Sci 2007;23(5):724-727

7 Monsef Kasmaei V, Asadi P, Zohrevandi B, Raouf MT. An epidemiologic study of traumatic brain injuries in emergency department. Emergency (Tehran) 2015;3(4):141-145

8 Paiva WS, Oliveira AM, Andrade AF, Amorim RL, Lourenço LJ, Teixeira MJ. Spinal cord injury and its association with blunt head trauma. Int J Gen Med 2011;4:613-615

9 Yattoo G, Tabish A. The profile of head injuries and traumatic brain injury deaths in Kashmir. J Trauma Manag Outcomes 2008;2(1):5

10 Chalya PL, Kanumba ES, Mabula JB, Giiti G, Gilyoma JM. Aetiological spectrum, injury characteristics and treatment outcome of head injury patients at Bugando Medical Centre in north-western Tanzania. Tanzan J Health Res 2011;13(1):74-81

11 Patil SS, Kakade R, Durgawale P, Kakade S. Pattern of road traffic injuries: a study from Western Maharashtra. Indian J Community Med 2008;33(1):56-57

12 Pedersen K, Fahlstedt M, Jacobsson A. Kleiven S, von Holst H. A national survey of traumatic brain injuries admitted to hospitals in Sweden from 1987 to 2010. Neuroepidemiology 2015;45(1):20-27

13 Adeleye AO,OlowookereKG,Olayemi OO.Clinicoepidemiological profiles and outcomes during first hospital admission of head injury patients in Ikeja, Nigeria. A prospective cohort study. Neuroepidemiology 2009;32(2):136-141

14 Ravikumar R. Patterns of head injuries in road traffic accidents involving two wheelers: an autopsy study. J Indian Acad Forensic Med 2013;35(4):342-359

15 Styrke J, Stålnacke BM, Sojka P, Björnstig U. Traumatic brain injuries in a well-defined population: epidemiological aspects and severity. J Neurotrauma 2007;24(9):1425-1436
16 Singha Y, Das G, Phukon S. Pattern of head injuries in fatal RTA's in tertiary care hospital, Assam. Int Med J 2014;1(4):149-152

17 Singh A, Meena RN, Sharma V, Kumar N, Meena LP. Evaluation of the incidence, nature of injury and clinical outcomes of head injuries in North-Eastern part of India. Int J Med Sci Public Health 2013;2:287-289

18 Caradoc-Davies TH, Dixon GS. Hospital morbidity due to head injuries in New Zealand in 1980-1988. Neuroepidemiology 1995;14(4):199-208

19 Gbalipre FB, Cliford OE. Pattern, outcome and management of head injury by general surgeons at the accident and emergency department of the Niger Delta University teaching hospital (Nduth) Okolobiri, Bayelsa state of Nigeria. Palgo J Med Medical Sci 2014;1:1-6

20 Hassan N, Ali M, Haq NU, et al. Etiology, clinical presentation and outcome of traumatic brain injury patients presenting to a teaching hospital of Khyber Pakhtunkhwa. J Postgrad Med Inst 2017;31(4):365-370

21 Kool B, Chelimo C, Ameratunga S. Head injury incidence and mortality in New Zealand over 10 years. Neuroepidemiology 2013;41(3-4):189-197

22 McIntyre A, Mehta S, Aubut J, Dijkers M, Teasell RW. Mortality among older adults after a traumatic brain injury: a meta-analysis. Brain Inj 2013;27(1):31-40

23 Rajeev K, Ashish J, Jayanthi Y, Dubey B. Pattern and distribution of head injuries in fatal road traffic accidents in Bhopal region of Central India. J Indian Acad Forensic Med 2015;37(3):242-245

24 Servadei F, Verlicchi A, Soldano F, Zanotti B, Piffer S. Descriptive epidemiology of head injury in Romagna and Trentino. Comparison between two geographically different Italian regions. Neuroepidemiology 2002;21(6):297-304

25 Andriessen TM, Horn J, Franschman G, et al. Epidemiology, severity classification, and outcome of moderate and severe traumatic brain injury: a prospective multicenter study. J Neurotrauma 2011;28(10):2019-2031 